\title{
Converting Traditional Engineering Physics Laboratories into Self-Designed Student Explorations
}

\section{Dr. Amy Biegalski P.E., University of Tennessee, Knoxville}

Dr. Biegalski is a lecturer in the Engineering Fundamentals Program at The University of Tennessee, Knoxville. She received her M.S. and Ph.D. in Structural Engineering from the CASE School of Engineering. She worked as a consulting structural engineer before joining UT. Her research interests include engineering fundamentals courses and project based learning; abiegals@utk.edu.

\section{Dr. Kevin Kit, University of Tennessee, Knoxville}

Kevin Kit is Director of the Engineering Honors Program and Associate Professor of Materials Science and Engineering at the University of Tennessee. He received a B.S. in Materials Engineering from Virginia Tech and M.S. and Ph.D. in Materials Science and Engineering from the University of Delaware. He currently teaches Honors Physics for Engineers for first-year students and Honors Introduction to Materials Science and Engineering. His engineering education interests include first-year engineering courses and the effect of intrinsic motivation on student success.

\section{Dr. Rachel McCord, University of Tennessee, Knoxville}

Rachel McCord is a a Lecturer in the Engineering Fundamentals Division at the University of Tennessee in Knoxville. She received her Ph.D. in Engineering Education from Virginia Tech. Her research interests include the impact of metacognitive and self-regulated learning development on engineering student success, particularly in the first year. 


\title{
Converting Traditional Engineering Physics Laboratories into Self-Designed Student Explorations
}

\begin{abstract}
This work in progress describes the initiative at University of Tennessee to redesign traditional first year engineering laboratories into self-designed learning experiences for several topics throughout the semester. In the traditional laboratories students followed an explicit set of procedures to solve an engineering problem. In the redesigned lab, teams of students are presented with a design challenge related to that week's lecture curriculum, supplied with applicable equipment and technology, and advised to self-design their own experiments and investigations. Learning objectives and background information are provided and students have instructor support for guidance and direction during their experimentation and analysis. The redesigned laboratories endeavor to build skills that address the modern needs of the engineering industry, self-designed learning and innovation, and aim to increase student comprehension and interest.
\end{abstract}

\section{Background}

With the advent of rapid technological development and the high demand for inventive design skills, the needs of the engineering industry are shifting away from the traditional engineering foundations of teamwork and fundamental science toward a revamped engineering skillset for this generation: innovation, self-motivation, and the ability to create a design amidst a dynamic set of constraints. It was posited that by redesigning some of the traditional first year engineering laboratories at the University of Tennessee into self-directed learning laboratories, we could still meet the traditional goals of having hands-on experiments to apply and build upon concepts learned in lecture, build the traditional skills necessary to succeed as an engineer, and also develop the high value skills of modern engineers. By giving the students the opportunity to play and self-design their own experiments, an additional intention of the redesigned laboratories was that the students could better experience the fascination of the science and thus have increased passion for engineering.

When students are presented with an application and take control of their own learning, research in cognition and learning theories and evidence from implementation in practice at universities indicates that students gain a more profound and comprehensive understanding of the material in addition to developing "the critical thinking and self-directed learning skills that characterize expert scientists and engineers." 1 Dym provides an overview of the substantial research evidence that first year cornerstone design-oriented engineering programs enhance student interest, retention, motivation in upper division engineering courses, and performance in capstone design courses, and suggests that significant design content was correlated to significant impact on retention. ${ }^{2}$ With today's increased design complexities, interdependencies, and constraints, Dym suggests that experiment design is one of the skills that designers and engineering students need (along with thinking about system dynamics, reasoning about uncertainty, and making estimates) and teaching experiment design will enhance students abilities to correlate between engineering models and experimental data. Litzinger summarizes multiple studies on inquiry-based science and engineering laboratories based on learning from 
experimentation; findings included an improved ability to design experiments and analyze data, enhanced conceptual knowledge, increased student interest, and increased ability to apply the learned concepts to a new problem. ${ }^{3}$ Higher education institutions are recognizing that selfdirected learning skills are essential for engineering students, and many (most notably WPI, Rose-Hulman, Harvey-Mudd, Olin) have built entire programs around non-traditional engineering education. In a recent study of survey results sent to the global engineering community to validate a series of desired competencies of today's engineers, respondents agreed that the most important attributes were the following: communicates effectively in a variety of different ways, methods, and media, possesses the ability to think both critically and creatively, and shows initiative and demonstrates a willingness to learn. ${ }^{4}$

ABET has recognized their role in assuring that engineering education follows the dynamic culture and needs of the industry. Since 2000 ABET Student outcomes [a-k] have remained relatively unchanged, but recently ABET proposed altering both the curriculum and the expected educational outcomes for engineering students, including expanding the "design and conduct experiments" outcome to "develop and conduct appropriate experimentation, analyze and interpret data, and use engineering judgment to draw conclusions.” 5 Other language added includes an ability to "apply both analysis and synthesis" in design. Cited reasons for the numerous changes include, to better "represent contemporary practice”, provide a clearer framework for assessing the outcomes, to provide richer, measurable, more balanced, and more realistic goals that better match today's environment ${ }^{6,7}$ and the "goal of encouraging innovation has not been achieved". 7

All of the engineering students at the University of Tennessee begin in our interdisciplinary Engineering Fundamentals Program, a curriculum built on design-oriented and problem-oriented hands-on team activities. Engineering physics is the cornerstone course in the program and includes three components: a lecture focusing on engineering applications of physics, larger design projects, and weekly laboratories. Many of our laboratories follow traditional engineering education practice; teams of students receive a detailed lab procedure form including a number of engineering hands-on problems and applications related to lecture that they must follow accurately for 75 minutes under guidance of their instructor. In these traditional laboratories, though the basic goal may be to apply and build upon concepts learned in lecture, the larger goal is to build skills necessary to succeed as an engineer - teamwork, communication, and problem solving. However, these conventional objectives, though still critical, are not fully aligned with the present goals of the industry - initiative and innovation.

It was determined to redesign a number of labs for our freshman engineering physics classes that would put the responsibility of learning in the students' hands and build self-directed learning abilities. In the redesigned lab, teams of students are presented with a design challenge related to that week's lecture curriculum, supplied with applicable equipment and technology, and advised to self-design their own experiments and investigations. After conducting their own experiments and investigations, student teams record their findings including the computational backings, and report their conclusions.

Certain laboratory topics lent themselves to be more suitable for the conversion into a selfdirected exploration lab based on the range of materials that could be given to the students and the possible directions the students could go with the equipment. For the redesigned labs, 
students are placed in a framework of scaffolded instruction: they are introduced the concepts during lecture, they are presented with background information and examples relating to the investigation, and when working through the lab facilitators are present for discussions, guidance, and direction. Thus far we have revamped three labs, one in an honors freshman engineering physics course and two labs in our mainstream freshman engineering physics course. All students in all sections participated in the revised labs such that all students could benefit from the experience and to ensure grading was done fairly; there were no "control” groups.

\section{Modification of Kinematics Lab in Honors Physics for Engineers I}

The Kinematics Lab is the first lab performed by entering freshmen in "Honors Physics for Engineers I”. It is performed by students in lab sections soon after lectures covering kinematics (relationships between position, velocity, acceleration; changes in position and velocity under constant acceleration). The format of this lab was changed for the Fall 2015 semester to allow students more control over how the measurements were conducted. It was hoped that the increase in control would also increase the students' level of engagement in the activity.

\section{Previous Format}

In years past, students arrived to lab with no prior knowledge of the activities they would be engaging in. They were supplied with two 4-foot-long, 6-inchdiameter PVC tube with a $45^{\circ}$ elbow at the end, multiple stop watches, tape measures, masking tape, and tennis balls. They were given very detailed instructions about how to release a ball down the tube and determine the position of the ball as a function of time. The students were told to measure the geometry of the tube (Figure 1), how many timers to use, exactly where the timers should stand, how to release the ball and communicate that event to the timers, and how many times to repeat the measurements. Some students were told to take

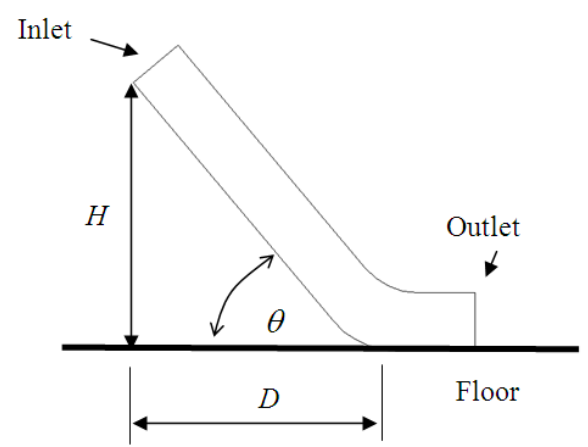

Figure 1. Honors Physics for Engineers I Kinematics Lab Geometry. measurements on a carpet floor and others on a wood floor. After collecting data, students worked in pairs to plot the position-time data on a supplied worksheet, and then to further construct instantaneous velocity-time and instantaneous acceleration-time plots. Students calculated the expected acceleration of the ball while it travelled down the tube and compared it to the calculated value. They were also asked to discuss possible random and systematic errors.

New Format (Fall 2015)

The cohort consisted of all 4 sections of approximately 30 students each. Students were asked to complete a pre-lab assignment that explained the basic experiment (similar to above), stated Objectives and Learning Outcomes, listed available materials and asked them to:

- $\quad$ Develop ideas about how their team could use the available materials to measure the position of the ball at different times 
- Develop ideas about how their team could use collected information to plot position, instantaneous velocity and instantaneous acceleration of the ball as a function of time - Think about the results they would expect based on their ideas.

They were required to bring their written ideas to recitation on the day of the lab. The instructions were much less prescribed compared to previous years. The materials available were very similar to the previous description except there was a third tube (5-foot-long, 2-inchdiameter) and variety of balls (racquet, tennis, golf). Each class of 30 was divided into three 10person teams and asked to discuss their pre-lab ideas for about 5 minutes, gather the materials they needed, and then collect the data. Then each team was further subdivided into eight teams of three or four people for analysis of the data and tasked to construct plots of position, instantaneous velocity and instantaneous acceleration versus time. In addition to comparing actual and expected accelerations in the tube and answering the same question about sources of error, each student was also asked to discuss how the data collection method they actually used compared to the ideas they developed as part of the pre-lab assignment.

\section{Results for Honors Physics for Engineers I Lab}

Overall, the quality of the position, velocity, and acceleration curves were similar to past years. The faculty and teaching assistants thought the lab went more smoothly than previously, which may be attributed to the pre-lab introduction to the overall scope of the lab. The engagement level of the students may have been better but certainly did not seem worse than previously.

Eighty-six percent of student teams responded to the question about differences between the planned and actual data collection methods used. Most student teams stated that after initial experiments, they had to increase the distance over which times were measured. Others stated that they:

- $\quad$ had to try several times to coordinate dropping the ball and starting timers.

- fixed the position of tube by taping it to the floor so that distances to marked spots on the floor were more consistent between repeats.

- $\quad$ adjusted data so that 0 position was at tube entry instead of tube exit.

- $\quad$ increased number of timers after initial experiments.

Overall, the instructors were pleased with the new format, and encouraged to see students realize they needed to modify their initial plans after actually collecting some data.

Honors instructors plan to modify more labs in the Spring sequence of this course to a similar format (pre-lab exercise plus less prescribed lab instructions). Possible topics are oscillatory motion (pendulums and spring-mass oscillators), mechanical equivalent of heat, gas laws, and pressure-volume cycles.

\section{Modification of Statics and Stability Lab in Physics for Engineers II}

Exercises in stability principles were traditionally a component of our Statics Lab which is the first (non-project) lab in our "Physics for Engineers II" second semester freshman engineering course. In our stability lab and lecture, students apply traditional statics concepts (equilibrium 
equations, free body diagrams) with concepts of friction and impending motion in order to analyze and understand stability of a system. Implementation of the redesigned lab occurred in all 22 laboratory sections of students, each section divided into six four-person teams.

\section{Previous Format}

After lectures covering statics and stability, student teams performed a number of prescribed hands-on experiments with a static ruler, spring scale, and weight, answered concept questions on applications in statics and stability, and then were instructed to evaluate a ladder on a frictionless wall problem by drawing free body diagrams and moment diagrams on whiteboards at their tables. The topic of stability and ladder problem as presented proved to be difficult to conceptualize for some students and student enthusiasm waned by the end of the lab period, so a better approach was sought.

New Format (Spring Semester 2016)

Student teams were given a "ladder”, “wall”, weights, string, and scale, and provided with the learning objectives for the experiments. Student teams were presented with the framework that they are a team of engineers tasked with testing and analysis of a new ladder product, and they needed to develop recommendations for safety regulations for the stability of the ladder to be distributed to consumers. Students were instructed to design and perform experiments and calculations to analyze the stability of the ladder. The teams were required to submit a Safety Evaluation Report which described their recommendations on the safety regulations for the stability of the ladder and describe the process their team used to determine the safety

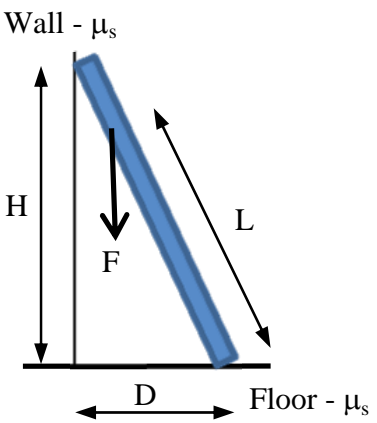

Figure 2. Physics for Engineers II Stability Lab Geometry guidelines. In addition to the supplied equipment, protractors and tape measures were included in each team's toolkit that they have for use throughout the semester. Teams were also required to upload a photo of a free body diagram and moment equation used in their analysis.

It was anticipated that the students would make safety recommendations on the angle of the ladder, the weight of the person on the ladder, and the safe height up the ladder (e.g. which rung), however none of these were prescribed to the students, it was up to them to determine what regulations they could test for that might be applicable to a real ladder.

\section{Modification of Resistors in Electrical Circuits Lab in Physics for Engineers II}

The third redesigned lab occurred in the third "module" of our "Physics for Engineers II" second semester freshman engineering course which addresses the concepts of electricity and magnetism as applicable to engineering practice. The implementation of the redesigned lab occurred in all seven laboratory sections divided into six four-person teams. The format was changed for the Fall 2015 semester to give students more freedom for building circuits and taking measurements, allow for a more in-depth understanding of the concepts, and to build enthusiasm, camaraderie 
and self-directed learning skills with their new mid-semester team by allowing students to design their own experiments.

\section{Previous Format}

After lectures covering Ohm's Law and Kirchoff's Rules and a hands-on laboratory practicing basic circuit building and multimeter skills, in the Resistors in Electrical Circuits Lab student teams were given a circuit board, batteries, multimeter, and a variety of resistors. Students worked through a prescribed lab procedure where they selected specific resistors, measured individual resistances, connected the resistors in series and then parallel, measured and compared measured vs. calculated values, built a simple circuit and then a whetstone bridge using prescribred resistors and arrangements, again measuring and comparing measured vs calculated values. After concluding the hands on activities, students worked a strain gage word problem (no lab equipment), a common engineering application of resistors.

New Format (Fall Semester 2015)

Students were given the same supplies, a circuit board, batteries, multimeter, and a variety of resistors. Students were presented with learning objectives and instructed to design and build a circuit, take measurements using their multimeter, and perform calculations to meet the learning objectives. Teams were required to upload a photo of the circuit they designed, and a corresponding data page with a circuit diagram, recorded measurements, and calculations and results.

\section{Assessment for Physics for Engineers II labs}

Though the goal to increase student learning and readiness for self-directed learning is straightforward, quantitative assessment of how one laboratory's activities have met this goal is challenging. For the Physics for Engineers II labs we chose to implement student selfassessment on completing the lab's objectives to be performed immediately at the end of the laboratory exercise. Three learning objectives were identified, and in separate iterations, either as individuals or teams, students were asked to fill out and submit a web-form evaluation, as shown below:

Rate your (group's) achievement on completing the lab's objectives:

5 - I (We) have an excellent grasp of these objectives

4 - I (We) have a better understanding of these objectives

3 - I (We) have an average understanding of these objectives

2 - I (We) did not learn much about these objectives

1 - I (We) did not learn anything about these objectives

Qualitative methods are also valuable in evaluating student progress on the objectives. Instructor observation, student interviews, and reviews of team reports allow for a more detailed understanding of the success of the project. For the redesigned Physics for Engineers II labs, instructors were able to observe the lab, interview students and graduate teaching assistants, and review the project reports to determine if the students were able to successfully apply and 
synthesize their knowledge to successfully design experiments, evaluate data, and form conclusions.

Grading assessment was analogous to our traditional lab grading which is based on participation, if the student teams performed all tasks and submitted all deliverables; they received full credit for participation that period.

\section{Results for Physics for Engineers II labs}

Preliminary results of the student surveys suggest that the students thought they made successful progress on the learning objectives. The learning objectives that were evaluated during this initial implementation of the program were specific to the physics concepts practiced in the lab. For the Physics for Engineers II Stability lab, 100\% of teams responded, and 81\% stated that they had either an excellent grasp of the learning objectives or a better understanding after performing the laboratory. For the Physics for Engineers II Resistors lab, 78\% of students responded, and the survey was divided into student's individual assessment of their achievement on completing each of three learning objectives. For the three objectives, $67-75 \%$ of students stated that they had either an excellent grasp of the learning objective or a better understanding after performing the laboratory. Faculty review of the students' deliverables (free body diagrams, circuit diagrams, photos, analysis, and conclusions) and observations of the students during labs, together with survey results, indicated that students were able to meet all of the former objectives of the lab, practice the same skills and concepts as before, with less prescribed instructions.

Because of the success of the initial implementation, we plan to incorporate additional opportunities for self-directed learning and innovation into the course. The initial redesign involved relatively simple and limited equipment as a first examination of how students would react to the given freedom. We hope to further improve upon the idea by offering more options, more directions to go, and more engineering applications. For example, for the resistors lab, in addition to the basic circuits, we could also incorporate strain gages and potentiometers. We are considering reframing more of the labs into one day or longer term projects, which would involve more detailed analysis in student reports and the opportunity for more reward (more weight in assessment) for innovation and effort. Also it seemed successful to put the labs into a framework of a client, user, and set of constraints; therefore where feasible that format will be implemented, and community service based investigations would also be a great addition.

Future planned adjustments of the quantitative assessments in these labs would be to try an approach similar to the IDEA assessment (from the IDEA Center at Kansas State) which evaluates progress on learning objectives as opposed to rating understanding of learning objectives. The IDEA system uses a 1 to 5 scale where students select from: no progress, slight progress; moderate progress, substantial progress, and exceptional progress. Another improvement we could adapt from the IDEA methodology would be to have students assess their progress on more general learning objectives not specific to the material, such as "Rate your progress on developing skills, competencies, and points of view needed by professional engineers" (IDEA Objective No 4). It was also realized that a much better survey response rate could be achieved by calling for students to complete the surveys before leaving lab; so that approach will be incorporated into future student feedback forms. 


\section{Conclusion}

The self-designed play based engineering laboratory can meet the typical goals of a traditional laboratory but also help develop the high value innovation and self-directed learning skills for modern engineers and increase student enthusiasm. Faculty review of student analyses and observations of the students during labs, together with some initial survey results, seem to qualitatively suggest that students were able to have the same or better comprehension of the concepts of the lab as compared to following predetermined laboratory procedures. Future enterprises of this project at University of Tennessee include redesigning more labs, increasing freedom, complexity, and engineering applications within the redesigned labs, enhancing student motivation to be more creative and innovative and improved assessment methods. Aside from meeting the needs of the changing culture of engineering by increasing initiative, innovation, and self-directed learning skills, this project also endeavors to increase student comprehension and enthusiasm.

\footnotetext{
${ }^{1}$ Prince, Michael J., and Richard M. Felder. "Inductive teaching and learning methods: Definitions, comparisons, and research bases." Journal of Engineering Education, 95.2 (2006): 123-138.

${ }^{2}$ Dym, C. L., Agogino, A. M., Eris, O., Frey, D. D. and Leifer, L. J. “Engineering Design Thinking, Teaching, and Learning.” Journal of Engineering Education, 94 (2005): 103-120.

${ }^{3}$ Litzinger, Thomas, et al. "Engineering education and the development of expertise." Journal of Engineering Education, 100.1 (2011): 123-150.

${ }^{4}$ Hundley, S.P. “The Attributes of a Global Engineer Project: Results and Recommendations from a Multi-Year Project.” ASEE 2015 International Forum. Seattle, WA June 2015 (2015): 1937 1-7. https://peer.asee.org/collections/19.

${ }^{5}$ ABET. Proposed revisions to criteria for accrediting engineering programs definitions, general criterion 3 student outcomes, and general criterion 5 curriculum (2015). www.abet.org/wp-content/ uploads/2015/11/Proposed-Revisions-to-EAC-Criteria-3-and-5.pdf. Accessed 22 Jan 2016.

${ }^{6}$ Rogers, K.J. “A Work in Progress.” Inside Higher Ed, Sept.1, 2015. www.insidehighered.com/views/2015/09/01/essay-responds-criticism-possible-changes-accreditation-standardsengineering. Accessed 22 Jan 2016.

${ }^{7}$ ABET. "Proposed revisions to ABET Criterion 3 (Student outcomes [a-k]) and Criterion 5 (Curriculum)" presented at the ASEE Annual Conference July 2015, Seattle, WA (2015). http://www.ecedha.org/docs/defaultsource/2015-speaker-presentations/abet-workshop-slides.pdf?sfvrsn=0. Accessed 22 Jan 2016.
} 